\title{
Reflexiones en torno a la estética apofática de Amador Vega
}

\author{
ZENIA YÉBENES ESCARDÓ \\ Departamento de Humanidades \\ Universidad Autónoma Metropolitana-Unidad Cuajimalpa \\ zyebenes@correo.cua.uam.mx
}

\begin{abstract}
Resumen: En su estudio en torno a las relaciones que existen entre estética y religión, Amador Vega ha desarrollado una investigación sobre la estética apofática en la que estudia los lenguajes de la negatividad en el arte contemporáneo. En este artículo me propongo señalar algunas interrogantes y posibles vías de reflexión que suscita la propuesta de Amador Vega y que pueden contribuir a mostrar la complejidad de las relaciones entre religión y estética.
\end{abstract}

Palabras clave: teología negativa, ascetismo, experiencia mística, abstracción

\begin{abstract}
In the study of relations between aesthetics and religion, Amador Vega has developed a line of research on Apophatic Aesthetics, in which he studies the languages of negativity in the field of modern art. My purpose in this article is to raise some questions about the Apophatic Aesthetics and to suggest how Amador Vega's research contributes to keep open the possibility of thinking the relations between aesthetics and religion.

Key words: negative theology, ascetism, mystical experience, abstraction

Es así como él pinta (pero aquí este verbo puede desplegar sus sentidos hasta tocar las distintas modalidades del arte) es decir, en primer lugar, como "representa" en el sentido propio en que esta palabra quiere decir "hacer intensa la presencia de una ausencia en tanto que ausencia".
\end{abstract}

JEAN-LUC NANCY*

En su obra de 1967 De l'absence et de l'inconnaissance de Dieu d'après les écrits aréopagitiques et Martin Heidegger, Christos Yannaras argumentaba que, a partir de cierta lectura heideggeriana, el análisis del nihilismo europeo y de "la muerte de Dios" no haría sino mostrar una crisis interna de la metafísica, que podría comprenderse como cierta forma de teología apofática y que abriría posibilidades inusitadas al pensamiento. Según esta lectura —a la que se sumará Jean-Luc Marion—, la destrucción de los conceptos metafísicos de Dios, de todos los "ídolos

* Jean-Luc Nancy, Noli me tangere. Ensayo sobre el levantamiento del cuerpo, trad. María Tabuyo y Agustín López, Trotta, Madrid, 2006, p. 81. 
racionales", alcanzaría su culminación en Nietzsche y abriría la posibilidad de pensar y expresar una trascendencia divina, tal y como fue previamente desarrollada por la tradición apofática dionisiana del siglo vi. La muerte de Dios llevaría así a cabo la desaparición de todos los obstáculos racionales que impedirían la verdadera visión de lo invisible. ${ }^{1}$

Desde una inquietud semejante a la de Yannaras o Marion, la tentativa heideggeriana de John Caputo y Reiner Schürmann optará por centrarse menos en la figura fundacional del Pseudo Dionisio Areopagita para explorar el carácter apofático del pensamiento de Meister Eckhart y Tomás de Aquino. Schürmann vinculará la comprensión existencial heideggeriana del Gelassenheit a la práctica del gelâzenheit en el misticismo de Meister Eckhart. Caputo subrayará la presencia de un elemento místico en la filosofía heideggeriana (procedente de la lectura que Heidegger hizo de Eckhart) y detectará en el intellectus de Tomás de Aquino una forma de pensamiento religiosa y mística que logrará salir indemne de la crítica del mismo Heidegger a la ontoteología. ${ }^{2}$

Por otra parte, como si obsesionara al pensamiento contemporáneo, en aproximaciones más recientes e inclinadas a la historia y al psicoanálisis, el interés en la teología apofática se ha visto mediatizado por las figuras de Jacques Lacan $^{3}$ y Michel Foucault, a través, por ejemplo, de la obra crucial de Michel de Certeau. Para de Certeau, la desintegración que empieza a experimentarse en el medioevo, y que da lugar al nacimiento de la modernidad, genera nuevas formas históricas de espiritualidad en las que la ausencia de Dios se experimenta a través del deseo y el duelo. ${ }^{4}$ En trabajos análogos, Michel Foucault analiza si la llamada "desaparición del sujeto" puede considerarse una forma contemporánea de teología negativa. ${ }^{5}$ Por otra parte, la tendencia postheideggeriana ha querido ver en la deconstrucción de Jacques Derrida

${ }^{1}$ Originalmente escrito en griego, el libro de Yannaras fue traducido por Jacques Touraille al francés en 1971; cfr. J.-L. Marion, L'Idole et la distance (1977); y Dieu sans l'être: Horse-texte (1982).

${ }^{2}$ Cfr. J. Caputo, The Mystical Element in Heidegger's Thought (1978); y Heidegger and Aquinas (1982). Cfr. R. Schürmann, Meister Eckhart: Mystic and Philosopher (1978).

${ }^{3}$ Cfr. D. Tracy, "Mystics, Prophets, Rhetorics: Religion and Psychoanalisis"; también E. Wyschogrod, Lacan and Theological Discourse (1989).

${ }^{4}$ Cfr. M. de Certeau, La fábula mística (1993).

${ }^{5}$ Cfr. J. Bernauer, "The Prisons of Man: An Introduction to Foucault's Negative Theology", pp. 365-380. 
una suerte de teología negativa no exenta de consecuencias éticas ni políticas. ${ }^{6}$

Pensar a través de la muerte de Dios (y habría que preguntarse si no es esto precisamente el cristianismo ${ }^{7}$ implica confrontar una serie dinámica de crisis. Tras la muerte, o las muertes de Dios en la modernidad, ¿cómo conocemos la pérdida o ausencia de lo divino? (y subrayo la ambigüedad del genitivo). ¿Cómo se vincula esta ausencia - como quiera que la comprendamos- con las heridas incurables de un sujeto que se quiso alguna vez autónomo y transparente a sí mismo? Lo interesante de todas estas preguntas contemporáneas es que, como bien lo señala Amador Vega, tienen que ver con la puesta en cuestión del lenguaje y la representación. ¿En qué sentido las fallas del lenguaje y la representación —sus puntos ciegos- no son accidentes que se pueden evitar con mayor o menor pericia, sino algo inherente y esencial a su operatividad misma? Y si es así, ¿qué posibilidades de pensamiento se avizoran desde aquí? Esta preocupación por el lenguaje y la representación ha permitido que a menudo sea el arte el que asuma el reto de acoger el misterio que custodiaron tan celosamente las religiones. No parece interesar tanto señalar si ese misterio se refiere a una divinidad incognoscible (cuya forma de presencia sería paradójicamente la ausencia) o a las fisuras abismáticas de una subjetividad finita puramente humana (lingüística y opaca a sí misma), sino apuntar a los procedimientos por los que el arte - formulando y transmutando los principios que ya se hallan en la tradición apofática y premoderna del pensamiento occidental- se hace cargo de una puesta en cuestión que contribuye a una apertura radical de lo real de la que, posiblemente, puedan atisbarse algunas consecuencias.

Hay que señalar que esta inquietud está lejos de ser espuria si recordamos que -desde las tensiones generadas por el aniconismo bíblico hasta las imágenes explosivas de Dios analizadas por Alois M. Haas-

${ }^{6}$ Cfr. J. Derrida, "Post-Scriptum: Aporias, Ways and Voices", pp. 283-323; para una valoración interesante de la ambigüedad de la postura derridiana al respecto, cfr. J. Caputo, The Prayers and Tears of Jacques Derrida: Religion without Religion (1997).

${ }^{7}$ Cfr. Filipenses 2:7. La formulación de una "muerte de Dios" ocurre explícitamente en el famoso himno luterano de Johannes Rist de 1641. No obstante, Hegel es quien desarrolla esta formulación sistemáticamente. Será la muerte de Dios desarrollada por Hegel (aunque pasada por el filtro de Nietzsche) la que retomará el teólogo Thomas J.J. Altizer, el representante moderno de la teología de la muerte de Dios, que mantiene diferencias significativas con Marion y Yannaras. Sobre Hegel, cfr. D. Kolb (comp.), Hegel's Philosophy of Religion (1992); cfr. también T.J.J. Altizer, Total Presence (1980). 
la vinculación sensible/inteligible ha sido preocupación esencial de la teología negativa. ${ }^{8}$ En una lectura distintiva, que se gesta desde Zen, mística y abstracción, Arte y santidad: Cuatro lecciones de estética apofática, y sus trabajos sobre Tàpies, Rothko u Oteiza, Amador Vega va dilucidando una estética apofática que, tal y como él mismo lo señala, "requiere una comprensión de la negatividad entendida como una vía ascética del pensamiento, con la idea de disponer de un campo de visión de la realidad que consiga evitar los límites conceptuales sujetos al campo semántico de lo trascendente-inmanente". 9 Apoyado en un sólido conocimiento de la mística medieval, patente en sus trabajos sobre Meister Eckhart y Ramón LLul, Vega decide mantener el término apofático para respetar la "vocación dionisiana" de esta estética en la que la negación no constituiría un movimiento autónomo, sino el momento destructor de todo proceso creador, previo a la afirmación o a la capacidad de respuesta. Ahora bien, para comprender el alcance de esta vocación dionisiana, sería necesaria una relectura contemporánea que nos ayudara a dilucidar en las fuentes de la tradición la oposición entre teología catafática y apofática y la lectura según la cual la teología negativa constituiría un mero reverso de la positiva, permaneciendo, por lo tanto, dentro de su lógica.

La pregunta es ¿a qué se refiere Amador Vega cuando habla de la negación como momento que precede a la afirmación o a la capacidad de respuesta? ¿Se halla esa afirmación dentro de la alternativa afirmación/negación? ¿O más bien — como parece sugerir — signa un "ni esto, ni aquello" en que la negación teológica supone una negación antropológica que nos desposee de las estructuras cognoscitivas habituales, haciéndonos — como señala San Juan de la Cruz- "saber toda ciencia trascendiendo"? Hay que señalar que esta desposesión no se daría necesariamente a través de lo que influidos por un sesgo psicologista llamamos fenómenos extraordinarios de conciencia, sino que paradójicamente un despliege explosivo de la plenitud de la imagen produciría la impresión de una invisibilidad, inabarcabilidad y ocultamiento que estaría más allá de toda comunicabilidad mediatizada.

Y, no obstante, si esto es así, ¿tendría sentido seguir haciendo una distinción entre lo apofático y lo catafático como dos procedimientos claramente distinguibles? A menudo la distinción se utilizó para definir un misticismo especulativo que frente a uno corporal o afectivo tendría un carácter más elevado (y la distinción podría desplazarse para la

${ }^{8}$ Cfr. A.M. Haas, "La nada de Dios y sus imágenes explosivas".

${ }^{9}$ A. Vega, "Estética apofática y hermenéutica del misterio. Elementos para una crítica de la visibilidad", incluido en este número, p. 9. 
diferencia entre una estética que privilegie la desfiguración y abstracción frente a la figuración y la representación). No obstante, estudios como los realizados por Caroline Walker Bynum o Amy Hollywood ${ }^{10}$ han apuntado el carácter apofático que parecen tener en el misticismo las mismas visiones corporales e imaginarias, subrayando la necesidad de repensar este tipo de distinciones de raigambre agustiniana. ${ }^{11} i$ No tendría la misma imagen la potencialidad de ser "leída" de manera catafática o apofática? ¿No podría ser que a veces la imagen más figurativa operara negativamente - pienso en ciertas representaciones de la Pasión de Cristo- y que a veces la más abstracta nos llevara en cambio a positivizar la realidad? ¿O no pudiera ser que hubiera cierto grado de indeterminación entre una y otra cosa que nos impidiera decantarnos con certeza por una u otra posibilidad? ¿No será que la clave está precisamente en esta indeterminación?

Se me puede responder que el procedimiento místico realiza jerarquías y diferenciaciones que posibilitan al mismo tiempo la distinción moral e intelectual. Por supuesto. El problema es que el mismo procedimiento místico establece las jerarquías para colapsarlas. Lo alto es lo más bajo, la nada es todo, y una acaba rogándole a Dios que la libere de Dios (y sospechando de paso que Dios no es sino la necesidad de vaciarse de Dios mismo). La pregunta, entonces, sigue en pie: ¿no consistiría el procedimiento místico finalmente en sabotear una distinción que parece hacerse siempre con fines de transmisión y en la que siempre se teme, como escribía San Juan de la Cruz, que no comprendamos que: "si es espíritu ya no cae en sentido; y si es que pueda comprenderlo ya no cae en puro espíritu"? ¿Y no sabotearía esta misma distinción a la estética apofática a la que se refiere Amador Vega, que se convertiría por ello en un procedimiento paradójico? Habría entonces una analogía, si no de atribución, sí de relación entre el procedimiento místico y el estético que habría que subrayar más. La estética apofática, como teología negativa, sería en sí misma una paradoja, una imagen explosiva, cuyo funcionamiento convendría explorar como tal.

Hay que señalar que he hablado de una analogía de relación y no de atribución, porque el preámbulo que Amador Vega señala para la esté-

${ }^{10}$ Cfr. C.W. Bynum, Fragmentation and Redemption (1991); A. Hollywood, The Soul as Virgin Wife (2001).

${ }^{11}$ San Agustín distingue entre visiones corpóreas, espirituales e intelectuales, $c f r$. J.-P. Migne (comp.), De Genesi ad litteram, en Patrologia cursus completus: Series latina (1844-1864); cfr. también Bernardo de Claraval, Sermones super Cantica canticorum, en J. Leclerq y H.M. Rochais (comps.), Sancti Bernardi Opera (19571977). 
tica apofática es una hermenéutica del misterio no religioso o teológico (si bien una seria consideración de lo apofático llevaría precisamente más allá de la alternativa simple entre teísmo/ateísmo, religioso/no religioso, mística/nihilismo, como el mismo Vega ha explorado; y pienso aquí en Michel de Certeau, que consideraba que lo apofático implicaba no reificar nada y no descartar nada, ni siquiera a las instituciones tradicionales mismas). ${ }^{12}$ Desde la propuesta de Vega, la capacidad sacramental del arte moderno depende de su acogida a un misterio que no tiene nada que ver con un secreto de los orígenes. Efectivamente, Mark C. Taylor ha señalado espléndidamente las complicidades que hubo entre ciertas corrientes vanguardistas del siglo xx y los regímenes totalitarios en su anhelo religioso por la pureza del origen. ${ }^{13}$ Desde la tradición cristiana, con la que estoy más familiarizada, Michel de Certeau piensa el cristianismo como aquello que sólo es a partir de la desaparición de su origen (Cristo). El cristianismo no es sino el movimiento paradójico que consiste en repetir el movimiento por el cual el origen se borra a sí mismo. No es sino esta llamada a ser desde un lugar ausente, a la que se responde reproduciendo ese no lugar infinitamente, y por ello no hay ninguna razón por la que no pueda encontrarse en tradiciones no cristianas. ${ }^{14}$ Tratando de trasladar al planteamiento de Amador Vega algunas de estas inquietudes, creo que el misterio al que él se refiere no es algo "dado" a lo cual haya que retornar, sino que tiene más bien que ver con el darse de una realidad que no es nada fuera de ese mismo darse. Se trataría de un "hacerse desde sí" de la realidad que nunca es un dato, sino el vivo arrebato de sí y el salto hacia la existencia manifiesta que sólo se manifiesta a sí misma, o a nada. Tal vez el misterio en el que Amador Vega contempla la invisibilidad de lo visible y la sacralidad de lo profano tenga que ver con lo que Jean-Luc Nancy llama la manifestación, lo que pasa con la creación del mundo cuando ya ningún creador está dado ni por inventar:

no hay —escribe Nancy— "algo-que-se-manifiesta", algo además de la manifestación misma. Tampoco hay espectador de la manifestación. Yo con mi saber estoy también en medio de la manifestación, estoy manifestado y

${ }^{12}$ Cfr. M. de Certeau, La debilidad de creer (2006).

${ }^{13}$ Cfr. M.C. Taylor, Disfiguring. Art, Architecture, Religion, pp. 98-142.

${ }^{14}$ Cfr. M. de Certeau, La debilidad de creer, pp. 191-311. Los planteamientos de de Certeau fueron criticados, entre otros, por su maestro Henri de Lubac, que veía peligrar la tradición de la Iglesia a la que de Certeau efectivamente no reconoce un privilegio especial. Cfr. F. Dosse, Michel de Certeau: el caminante herido (2003). 
eso lo manifiesto a mi vez. La manifestación es entonces desde sí misma o desde nada. ${ }^{15}$

Jean-Luc Marion ha hablado de fenómeno saturado en el sentido de una intuición que volvería al fenómeno paradójico hasta el punto de la no aparición. Un fenómeno que revertiría la condición del horizonte fenomenológico sobrepasándolo y no inscribiéndose en él y que revertiría la reducción trascendental porque, por así decirlo, se atraería al "yo", en lugar de dejarse reducir por él. ${ }^{16}$ Desde una perspectiva apofática, no obstante, no deberíamos perder de vista que estas categorías son útiles sólo desde el momento en que aceptamos desdecirlas evitando su reificación.

A través de procedimientos que van desde la fragmentación-desfiguración, la profanación-ambigüedad, el abandono-vacuidad, la duración y movimiento, o la levedad-densidad-gravedad, el arte apofático —nos dice Amador Vega - provoca una crisis de los propios límites expresivos y representativos, de manera que la dimensión perceptual de la realidad deba plantearse nuevamente. Vega destaca en este punto la necesidad de la empatía y la dispositio; ya que si ser humano significa, por así decirlo, estar constitutivamente en crisis, es necesario que el sujeto quiera saber la verdad de su ser individual para transformar la mirada. Dispositio, podemos preguntarnos, ¿como aquello que según Aristóteles indica o define la virtud misma?, ${ }^{17}$ ¿o dispositio como quiere Dewey, es decir, como la prontitud a elegir abiertamente de manera específica cada vez que se presente la oportunidad? ${ }^{18}$ La pregunta no es baladí porque Amador Vega habla de una ascesis del pensamiento. Las tradiciones religiosas que han trabajado con imágenes - pienso en la práctica cristiana de meditación utilizada especialmente por los franciscanos en el Medioevo, pero también en los mandalas del budismo Mahayana- ejercitan al sujeto en la práctica de la contemplación de imágenes en un entrenamiento que suele ser prolongado hasta que "algo" finalmente se desencadena. ¿Dispositio, entonces, como ejercicio sostenido a lo largo del tiempo, o como predisposición "más espontánea"?

Ahora bien, si el reclamo de la no intencionalidad de lo apofático se toma en serio, y si toda experiencia es por definición intencional, otra cuestión que ha de tomarse en cuenta es que lo que se desencadena

\footnotetext{
${ }^{15}$ J.-L. Nancy, Hegel o la inquietud de lo negativo, pp. 39-40.

${ }^{16}$ J.-L. Marion, Etant donné: Essai d'une phénomenologie de la donation (1997).

${ }^{17}$ Cfr. Met., V, 20, 1022 b 10; Ét. Nic., II, 7, 1107 b 16, 30.

${ }^{18}$ Cfr. J. Dewey, Human Nature and Conduct, p. 41.
} 
con el emerger de la obra de arte no parece ser lo que comúnmente entenderíamos por experiencia estética. Toda experiencia debe tener un objeto gramatical, pero parece que en la propuesta apofática éste se subvierte. Habría tres maneras de enfrentar el problema: 1) descartar lo apofático y buscar un objeto de experiencia; 2) repensar la noción de experiencia - como constructo moderno- de manera que incorpore aspectos no intencionales; 3 ) poner entre comillas el concepto de experiencia. Si, como señala Amador Vega, se hace necesario entonces concebir una dimensión perceptual en la que la distinción exterior e interior no sea relevante, o en la cual el sujeto que percibe lo haga desde un lugar que abarca tanto el afuera como el adentro, puesto que él mismo no se halla en el modo "común" de recepción, nos hallamos con que queda destruida toda mediación o representación objetiva (y con ella otro de nuestros supuestos más queridos, el de que toda experiencia es mediada). Haría falta entonces, a mi modo de ver, no sólo una antropología de los sentidos, sino también una antropología del despojamiento —análoga a la tanatología mística que propone Alois M. Haas- ${ }^{19}$ que apunte a ese vaciamiento del yo, a ese deshacerse de las estructuras cognitivas ordinarias en esta "experiencia" estética (que yo he decidido poner entre comillas) y en la que cabría preguntarse si lo que está en juego no es la experiencia de la ausencia, sino la ausencia de experiencia o la imposibilidad de distinguir entre ambas. ${ }^{20}$

Hay que señalar, además, que si, como hemos visto, esta "experiencia estética" implica el deshacerse de la lógica binaria del lenguaje y el pensamiento (yo/otro, arriba/abajo, antes/después, aquí/allí), no podemos decir tampoco que se trate propiamente de "algo", o que pueda ser "poseída". A través de estrategias particulares (desfiguración, vaciamiento, abstracción), la estética apofática induce en el espectador un acontecimiento que rehúsa la dicotomía sujeto-predicado. Un ver sin ser espectador. Sin embargo, este momento de indistinción sujeto-predicado es efímero, y puede reificarse en un nuevo objeto de experiencia. Una estética apofática debería reflexionar sobre los procedimientos que apuntan en ella a la tarea incesante de evitar la reificación, y ello supone reflexionar sobre lo que implica el carácter repetitivo de sus procedimientos (desfiguración, vaciamiento, abstracción,

${ }^{19}$ Cfr. A.M. Haas, "Mors Mystica: Thanatologie der Mystik, inbesondere der Deutschen Mystik", pp. 304-392.

20 "Experiencia" es un término problemático también en el estudio de la mística. Somos herederos de las concepciones del siglo XIX, pero lo cierto es que la palabra "experiencia" no aparece en los místicos antes del siglo XII y con implicaciones muy diversas. Cfr. J.-Y. Lacoste, Expérience et Absolu (2004). 
etc.). Dicho en otras palabras: una estética apofática debería poder dar cuenta, al mismo tiempo, del carácter repetititivo de sus estrategias, y de la vinculación entre repetición y acontecimiento que tradicionalmente testimoniamos en la performatividad de los rituales (hay que arrodillarse para acabar creyendo, dice Pascal; en la repetición surge la novedad radical de la fe, pero también, y por la capacidad generativa de la repetición creadora, en cada genuflexión dormita la herejía). Habría que considerar, entonces, la forma en que la repetición repite lo mismo pero difiere ${ }^{21}$ marcando los lugares en los que el acontecimiento irrumpe.

Volvamos, no obstante, al arte. El arte es objeto de contemplación y no de necesidad, formulaba sintetizando la tradición la alta escolástica. La verdad del arte, dice Amador Vega citando a Heidegger, implica pensar que ésta reside en su aparecer, en su emerger. La verdad de la manifestación, nos explica de nuevo Jean-Luc Nancy, "no está más allá como otra cosa sino como la no-cosa de la cosa, el no-ser del ser". ${ }^{22}$ Estética apofática, estética negativa, porque toda verdad está en lo sensible, pero lo está como negatividad. La representación sensible indica por sí misma que su verdad está en ella como fuera de ella, como manifestación que no es sino ese manifestarse mismo. Como si el fenómeno "saturado" que se da sin reserva fuera un exceso tan extremo que estaría sólo presente como ausente. Lo sagrado, nos recuerda el mismo Amador Vega en otro lugar, gracias a su ausencia determinada de forma, a su modo caótico de ser puede transformarse y devenir todas las cosas. ${ }^{23}$ En este sentido, la tarea del arte es una contención del lenguaje que transfigura las cosas y las presenta en una extraña pobreza, una sencillez ultraterrena, de tal manera que quedemos transfigurados por ellas y las veamos de nuevo bajo una nueva luz. Se trata de deber fidelidad a lo que Merleau-Ponty llamaba fe perceptiva, una fe exclusiva en lo visible - in-visibilidad- en la dificultad de lo visible y en los enigmas a que da lugar. ${ }^{24}$

${ }^{21}$ Derrida utiliza el término différance, que en su contenido semántico incorpora el doble sentido: a) de distinción o diferencia, y b) de dilación, tardanza y demora. La différance resalta la doble connotación del signo: diferenciar y diferir. Se trata de enfatizar la capacidad de repetición en la alteridad. Para Derrida, el acontecimiento nace de la repetición porque la repetición es un arma de doble filo: genera costumbre pero, al repetirse, altera, introduce la posibilidad de desvío. Cfr. J. Derrida, De la gramatología (2005).

${ }^{22}$ J.-L. Nancy, op. cit., p. 40.

${ }^{23}$ A. Vega, Arte y santidad. Cuatro Lecciones de estética apofática, pp. 23-45.

${ }^{24}$ Cfr. M. Merleau-Ponty, Lo visible y lo invisible (1966). 
Quizá por ello la estética apofática de Amador Vega acaba enlazando entonces, no con una metafísica, sino con una antropología de los sentidos en la que anhela, una vez más, repensar lo sensible/inteligible, lo sagrado/profano, lo visible/invisible, y en la que se intuye clave la apercepción que encuentra en Lull (antes que en Kant o en Leibniz) para pensar un espiritual sensible que cuestione antiguas dicotomías y antiguas jerarquías. ${ }^{25}$ Sentido, nos advierte Jean-Luc Nancy, es una palabra maravillosa que designa "los órganos de aprehensión inmediata" y "la significación, el pensamiento general de la cosa". ${ }^{26}$ El sentido de sentido, nos dice después, está en el paso de una a otra significación. El paso mismo, eso sí, no se deja aprehender en una tercera significación independiente:

El sentido no es el sentido del ser, como si fuera una propiedad dada, una significación ideal que flota por encima de él, y más o menos perceptible para el espíritu de los hombres. Es el ser como sentido, arrancado a la subsistencia y a la determinación fijada [...] La inquietud de lo negativo es la agitación, la tensión, el dolor y la alegría de una apropiación. ${ }^{27}$

Ahora bien,

la apropiación hace que una cosa no caiga meramente en mi dependencia [...] Lo propio es lo que llega en otro como si llegara en su sí-mismo; así como el sentido propio de una palabra es su manera de dar, a través de su definición en otras palabras, lo que supuestamente dice ella sola sin las demás. $^{28}$

Y no obstante, como señala el mismo Vega, la inquietud de lo negativo no acaece sin "Tomar la muerte como punto de partida y la negación del yo individual y creado; afectando por lo tanto a una nueva consideración del sujeto cognoscente y del subjetivismo." ${ }^{29}$ La crisis de los límites perceptuales, expresivos y representativos a los que apunta la estética apofática, ese despojamiento radical que toca la carne, me parece ineludible al pensar en una antropología en la que, parafraseando a San Juan de la Cruz: "para venir a verlo todo hay que venir a ver algo en nada". Si bien Amador Vega señala que esta autonegación no es un

${ }^{25}$ Cfr. A. Vega, Tratado de los cuatro modos del espíritu, pp. 139-171.

${ }^{26}$ J.-L. Nancy, op. cit., p. 52.

${ }^{27}$ Ibid., p. 57.

${ }^{28}$ Ibid., pp. 53-54.

${ }^{29}$ A. Vega, Zen, mística y abstracción, p. 61. 
suicidio sino la comprensión de la vida a través de la muerte, creo que tampoco aquí podemos ir demasiado rápido y que a ello apuntan sin ir más lejos itinerarios como el de Rothko o el de Paul Celan. El despojamiento, la radicalidad del vaciamiento de las estructuras cotidianas apunta a cierta indeterminación entre la nada relativa y la nada absoluta de Nishitani. "¿Cómo saber si se cae o se camina? Sólo es natural y siempre inminente el movimiento de caer", ${ }^{30}$ señala Michel de Certeau. En su extraño y hermoso texto "Extase blanche" [Éxtasis blanco], ${ }^{31} \mathrm{de}$ alguna manera próximo a Lo visible y lo invisible de Merleau-Ponty, el mismo de Certeau se refiere a la terrible visión de Dios, a los destellos aterradores de no ver nada cuando se ve a Dios, cuando desaparecen todas las formas que constituyen un mundo y el espíritu pasivo y deslumbrado se abandona a un neutro sin yo. ${ }^{32}$ Como en el arte, ver aquí es un "fuera de sí" y por tanto no es representación ni juicio, sino el chasquido inaprensible de la exterioridad, su infinita plasticidad, su multiplicidad, no su unidad. Ahora bien, ¿Cómo saber si se trata de la incertidumbre cognoscitiva radical, o del quizá que abre al otro?

Esta última posibilidad —la del quizá que abre al otro- es el motivo del film Tan lejos, tan cerca de Wim Wenders, que contempla en su arte la posibilidad de hacer que el espectador se percate de la potencialidad de la mirada. "La razón por la que hice esta película con ángeles fue por su manera de mirar las cosas [... . , que ellos pudieran hablarnos de una forma diferente de ver [...] en la cual no sólo tomas con la mirada, sino que también entregas con tus ojos." 33 La cámara cinematográfica se transforma así en un ojo icariano a través de cual unos ángeles - que no son metáforas del más allá, sino de la trascendencia de una vida otra desplazándose en el más acá de la inmanencia- perciben la esencia de las cosas. Con ellos, Wenders emprende un trayecto hacia el enigma de la subjetividad humana. La obligación corpórea para con el otro es posible únicamente para el ángel en el momento en que transmuta su condición y se encarna: es posible en cuanto apertura al carácter vulnerable de ser sensible. Es de este modo que la subjetividad angélica deconstruida se diseña por la santidad de la sustitución y que Wenders plantea una suerte de transferencia trascendente de la divinidad encar-

${ }^{30}$ M. de Certeau, La debilidad de creer, p. 295.

${ }^{31}$ M. de Certeau, "Extase blanche", Traverses, no. 29, octubre de 1983, pp. 16-18; se incluyó una versión en castellano en La debilidad de creer (véase la bibliografía).

${ }^{32}$ Ibid., pp. 313-316.

${ }^{33}$ Tomado de la cubierta del laserdisc de U2 Faraway So Close!, lanzado en agosto de 1994. Cfr. el análisis que hacen del film M. López Gil y L. Bonvecchi, "Wim Wenders y la distancia de la mirada", pp. 149-160.

Diánoia, vol. LIV, no. 62 (mayo 2009). 
nada a la encarnación del sujeto. El despojamiento, ciertamente doloroso, de la propia condición parece redundar no en la pura autonegación, sino en el descenso de la montaña y el abrazo al mundo. "Soy el ángel necesario de la Tierra puesto que, a través de mi visión, veis la Tierra de nuevo. Liberada de su escenografía rígida y persistente, impuesta por el hombre. Y en mis oídos oís su trágico zumbido", escribirá Wallace Stevens en The Necessary Angel. ${ }^{34}$ Como señala Simon Critchley:

Pasando por un momento de Stevens a Rilke, y reconociendo una inversión de la intencionalidad (en Stevens el ángel habla a los paysans, mientras que en Rilke el poeta habla al ángel), podemos vincular claramente, incluso basar la figura del ángel necesario en el imperativo de Rilke en la Novena Elegía del Duino, "Preise dem ángel die Welt, nicht die unsägliche" (Alabad este mundo ante el Ángel, no lo indecible). Esto quiere decir que hay que alabar este mundo al Ángel, el mundo visible y no el mundo invisible [... . Lo que asombrará al Ángel será que le hablen de lo más efímero de las cosas, lo que vemos por un momento, nosotros los más efímeros de los seres. ${ }^{35}$

Y no obstante, y antes de apresurarnos a poner punto final, habría que insistir que ningún golpe de dados abolirá jamás la indeterminación, y que sólo un acto que tiene consecuencias hace existir a un sujeto de ese acto. El ángel Cassiel se encarna sólo en el momento en que, "no sabiendo y toda ciencia trascendiendo", arriesga su vida por otro. En ese riesgo radical, el sujeto que adviene es siempre un poco extranjero, un poco extraño, una criatura que se sabe sin toda la soberanía. Sólo así nos escapamos de la sensación de que, como dice con gracia Félix Duque:

Todas las dimensiones de lo sagrado están aquí, presentes y a la mano, pero todo es fake. De que el falso ángel cibernauta no es mensajero de nada ni de nadie, sino de que se limita a entremezclar mensajes mediáticos ajenos sin responsabilidad alguna por ello. De que ni siquiera puede pecar y rebelarse contra Dios porque él mismo se cree un petit-Dieu, un niño cósmico que juega en el tablero de un mundo del que han desaparecido el llanto y la risa. ${ }^{36}$

Podemos pensar, si no es pedir demasiado al arte, que tenga al menos esta potencialidad transmutadora que fue y es todavía en muchos

${ }^{34}$ W. Stevens, Collected Poems, p. 471.

${ }^{35}$ S. Critchley, Muy poco. . . casi nada. Sobre el nihilismo contemporáneo, p. 196.

${ }^{36}$ F. Duque, Filosofía para el fin de los tiempos, p. 259. 
ámbitos patrimonio de las religiones. Habría que recordar también que esa potencialidad no le vendría al arte de sí mismo, sino de su capacidad para acoger el misterio; y que en esa capacidad basan también los símbolos sacramentales su poder para la conversio. La tradición mística cristiana tiene un largo itinerario favoreciendo prácticas meditativas en las que las imágenes de Cristo crucificado, a través de mecanismos complejos de memoria e identificación, provocan en el devoto el autovaciamiento y la conversión de la mirada, ${ }^{37}$ itinerarios de místicas como Angela de Foligno o Teresa de Jesús no se comprenden sin esta práctica que, iniciado el siglo Xx, retomará Georges Bataille en su Suma ateológica y en su búsqueda de lo que denominará "la experiencia interior". Estas prácticas al dirigirse a un cuerpo crucificado, y plantear con ello complejas cuestiones éticas que ciertamente habría que dilucidar, suponen un encuentro con la especificidad corporal, mortal y lacerada que, quizá, sea otra manera de acoger el misterio. ${ }^{38}$ En la visión del ángel, la tierra es vista de nuevo como por primera vez, pero despojada temporalmente de las "esposas forjadas por la mente" de Blake; ahora bien, al oír al ángel quizá no volvamos a la visión beatífica o a la inocencia natural, sino que tal vez oiremos, como señala Stevenson, el trágico zumbido de la tierra, el llanto humano, el sufrimiento humano, el inhumano sufrimiento. ${ }^{39}$ ¿A qué podría apuntar, entonces, la conversión de la mirada? Una voz angélica resuena en el fondo de la imagen en uno de los pasajes de la película de Wim Wenders: "Ahora sus ojos sólo pueden recibir. Reciben, observan, sus ojos ya no pueden dar. Olvidaron que la luz entra al corazón por los ojos y luego resplandece afuera por el ojo del corazón."

\section{BIBLIOGRAFÍA}

Altizer, T.J.J., Total Presence, Seabury Press, Nueva York, 1980.

Bernauer, J., "The Prisons of Man: An Introduction to Foucault's Negative

Theology", Internacional Philosophical Quaterly, vol. 27, no. 4, diciembre de 1987, pp. 365-380.

Bynum, C.W., Fragmentation and Redemption, Zone Books, Nueva York, 1991.

${ }^{37}$ Cfr. M. Carruthers, The Craft of Thought. Meditation, Rethoric and The Making of Images, 400-1200 (2000).

${ }^{38} \mathrm{El}$ problema se agudiza si tomamos en cuenta que el escándalo de la cruz puede rebasar el marco de una economía redentora. Cfr. V. Vittiello, Cristianismo sin redención (1997).

${ }^{39}$ Cfr. Para una vision sugerente de este "trágico zumbido", cfr. R. Schürman, Broken Hegemonies (2003), especialmente el epílogo. 
Caputo, J., Heidegger and Aquinas, Fordham University Press, Nueva York, 1982.

—, The Mystical Element in Heidegger's Thought, Ohio University Press, Athens, 1978.

- The Prayers and Tears of Jacques Derrida: Religion without Religion, Indiana University Press, Bloomington, 1997.

Carruthers, M., The Craft of Thought. Meditation, Rethoric and The Making of Images, 400-1200, Cambridge University Press, Cambridge, 2000.

Certeau, M. de, "Extase blanche", Traverses, no. 29, octubre de 1983, pp. 1618. [Versión en castellano: La debilidad de creer, trad. Víctor Goldstein, Katz, Buenos Aires, 2006, pp. 313-316.]

— L La debilidad de creer, trad. Víctor Goldstein, Katz, Buenos Aires, 2006.

_ _ La fábula mística, trad. Jorge Moctezuma, Universidad Iberoamericana, México, 1993.

Critchley, S., Muy poco... casi nada. Sobre el nihilismo contemporáneo, trad. Elisenda Julibert y Ramón Vilà Vernis, Marbot, Barcelona, 2007.

Derrida, J., De la gramatología, 8a. ed., trad. Óscar del Blanco y Conrado Ceretti, Siglo XXI, México, 2005.

_ Foshay (comps.), Derrida and Negative Theology, State University of New York Press, Nueva York, 1992, pp. 283-323.

Dewey, J., Human Nature and Conduct, 10a. ed., Southern Illinois University Press, Carbondale, 2002.

Dosse, F., Michel de Certeau: el caminante herido, trad. Claudia Mascaraua, Universidad Iberoamericana, México, 2003.

Duque, F., Filosofía para el fin de los tiempos, Akal, Madrid, 2000.

Haas, A.M., "La nada de Dios y sus imágenes explosivas", Er, Revista de Filosofía, nos. 24-25, 1998, pp. 13-34.

—_, "Mors Mystica: Thanatologie der Mystik, inbesondere der Deutschen Mystik", Freiburger Zeitschrift für Philosophie und Theologie, vol. 23, no. 3, 1976, pp. 304-392.

Hollywood, A., The Soul as Virgin Wife, University of Notre Dame Press, Indiana, 2001.

Kolb, D. (comp.), Hegel's Philosophy of Religion, State of University of New York Press, Albany, 1992.

Lacoste, J.-Y., Expérience et Absolu, Presses Universitaires de France, París, 2004.

Leclerq, J., y H.M. Rochais, Sancti Bernardi Opera, Editiones Cisterciensis, Roma, 1957-1977, 8 vols.

López Gil, M. y L. Bonvecchi, "Wim Wenders y la distancia de la mirada", en La imposible amistad. Maurice Blanchot y Emmanuel Levinas, Adriana Hidalgo, Buenos Aires, 2004, pp. 149-160.

Marion, J.-L., Dieu sans l'être: Horse-texte, Arthème Fayard, París, 1982.

—, Etant donné: Essai d'une phénomenologie de la donation, Presses Universitaires de France, París, 1997. 
Marion, J.-L., L'Idole et la distance, Grasset, París, 1977.

Merleau-Ponty, M., Lo visible y lo invisible, trad. J. Escudé, Seix Barral, Barcelona, 1966.

Migne, J.-P., Patrologia cursus completus: Series latina, Garnier, París, 18441864.

Nancy, J.-L., Hegel o la inquietud de lo negativo, trad. Juan Manuel Garrido, Arena, Madrid, 2005.

Schürmann, R., Broken Hegemonies, trad. Reginald Lilly, Indiana University Press, Bloomington, 2003.

— Meister Eckhart: Mystic and Philosopher: Translations with Commentary, Indiana University Press, Bloomington, 1978.

Stevens, W., Collected Poems, Faber, Londres, 1955.

Taylor, M.C., Disfiguring. Art, Architecture, Religion, The University of Chicago Press, Chicago, 1992.

Tracy, D., "Mystics, Prophets, Rhetorics: Religion and Psychoanalisis", en Françoise Meltzer, The Trial(s) of Psychoanalysis, The University of Chicago Press, Chicago, 1988, pp. 250-272.

Vega, A., Arte y santidad. Cuatro lecciones de estética apofática, Universidad Pública de Navarra, Pamplona, 2005.

—, Tratado de los cuatro modos del espíritu, Alpha Decay, Barcelona, 2005.

— Z Zen, mística y abstracción, Trotta, Madrid, 2002.

Vittiello, V., Cristianismo sin redención, trad. Miguel Ramos Sánchez, Trotta, Madrid, 1997.

Wyschogrod, E., Lacan and Theological Discourse, State University of New York Press, Albany, 1989.

Yannaras, C., De l'Absence et de l'inconnaissance de Dieu d'après les écrits aréopagitiques et Martin Heidegger, trad. Jacques Touraille, Editions du Cerf, París, 1971.

Recibido el 27 de octubre de 2008; aceptado el 19 de noviembre de 2008. 